\title{
SIMULATION OF THE PERFORMANCE OPTIMIZATION OF HARBIN YINGBIN INDUSTRIAL PARK IN CHINA
}

\author{
Liu, F. L. ; Wu, W. W. ${ }^{* *} ;$; Liu, Y. X. ${ }^{* *} \&$ Klimov, L. ${ }^{* * *}$ \\ *College of Civil Engineering and Architecture, Harbin University of Science and Technology, Harbin \\ 150080, P.R. China \\ ${ }^{* * *}$ School of Management, Harbin Institute of Technology, Harbin 150001, P.R. China \\ ${ }^{* * * *}$ School of Physics and Technology, Ural Federal University, Ekaterinburg 620002, Russia \\ E-Mail: wuweiwei@ hit.edu.cn ( ${ }^{\#}$ Corresponding author)
}

\begin{abstract}
An effective performance optimization of industrial parks is urgently needed because of the importance of these parks. To develop a model to optimize the performance of industrial parks from the comprehensive perspectives of economy, society, and environment, the member assessment model was initially constructed to evaluate the comprehensive performance of enterprises. Then the assembly line balance (ALB) model and the mixed integer linear programming (MILP) method were integrated to construct a model (MILP-ALB) for evaluating the optimized comprehensive performance of an industrial park. This model was applied to Yingbin Industrial Park in Harbin, China. Simulation results indicate that the comprehensive performance of enterprises and their interactions determine the comprehensive performance of the industrial park. Results also demonstrate that the MILP-ALB model is applicable in evaluating the optimized comprehensive performance of the industrial park. Furthermore, the model can reveal the effects of the newly introduced enterprise on the optimized performance. Given these results, the model is a useful tool for performance optimization.

(Received in February 2015, accepted in October 2015. This paper was with the authors 3 months for 1 revision.)
\end{abstract}

Key Words: Industrial Park, Comprehensive Performance Optimization, MILP Model, ALB Model, Simulation

\section{INTRODUCTION}

Industrial park development projects, which are an effective approach to achieve economic development, are receiving increasing attention from governments of various countries worldwide [1]. Circular economy theory states that in industrial parks, wastes from one industrial process can serve as raw materials for another [2], and producers and consumers of materials, energy, and wastes form an ecosystem. Thus, industrial parks are a community of enterprises, which aims to obtain a high comprehensive performance by collaborating environmental management and reuse $[3,4]$. The comprehensive performance of the industrial park includes economic, social, and environmental benefits. The economic benefits have received more attention than social and environmental benefits in China's industrial parks [5, 6]. According to the Ministry of Industry and Information Technology of the People's Republic of China, from January to June 2014, 222 national industrial parks yielded US\$ 421.646 billion, added valued in tertiary industry of US\$ 140.365 billion, fiscal revenue of US\$ 118.995 billion, and tax revenue of US\$ 100.657 billion, with year-on-year growth by $12.3 \%, 14.7 \%, 18.7 \%$, and $15.2 \%$, respectively, which are higher than the national growing rates $(7.2 \%, 8 \%, 8.8 \%$, and $8.5 \%$, respectively) by $5.1 \%, 6.7 \%, 9.9 \%$, and $6.7 \%$, respectively. The survey of 18 industrial parks by All-China Environment Federation showed that $100 \%, 78 \%$, and $17 \%$ of industrial parks have water, air, and solid waste pollution, respectively. High economic benefits but low environmental and social benefits do not result in optimal performance but hamper the development of the industrial park. Hence, how to optimize the comprehensive performance of industrial parks to achieve harmonious development of economy, environment, and society is a problem that needs to be solved. 


\section{LITERATURE REVIEW}

Numerous researchers have focused on optimizing the performance of industrial parks. Efforts are particularly expended to mathematical modelling of the performance optimization of industrial parks. The models of performance optimization of industrial parks are mostly based on the following theories: Input-Output Theory [7, 8], Complex Systems Theory [9, 10], Network Theory [11, 12], and Mathematical Programming Theory [13, 14]. Different models focus on various aspects of industrial park performance.

Several models emphasize the economic issues of industrial parks because promoting economic growth is an important function of industrial parks. Kong et al. [15] focused on cost reduction. Their group developed a dynamic mixed integer linear programming (MILP) model to optimize by-product distribution, which provided the optimal solution in terms of total cost reduction. Given the increasing attention paid to environmental issues, many scholars begin to emphasize the environmental performance of industrial parks. For example, Taskhiri et al. [16] proposed an MILP model to minimize the energy of an interplant water network in an industrial park. This model considered the environmental effects of water use, energy consumption, and capital goods within an industrial park in a balanced approach. Tian and Zhao [17] developed an energy network flow model based on the energy hub concept model to model and optimize the energy network flow for the energy conservation and emission reduction in the Big Harbor Industrial Park. Environment-focused models usually provide technical supports for resource saving and environmental friendship.

A well planned, functioning industrial park is speculated to benefit the economy and substantially relieve environmental pressure in and near the location of its development [18, 19]. Scholars have attempted to integrate different aspects of performance to obtain a holistic understanding of the industrial park. For example, Aviso et al. [20] constructed a bi-level fuzzy optimization model for optimizing the water exchange network of plants in an ecoindustrial park to investigate the effect of charging fees for the purchase of freshwater and treatment of wastewater. This model particularly focuses on the economic and environmental benefits of industrial parks. Gu et al. [21] investigated on material and energy of an industrial park and proposed an essential mathematical optimization model. The model serves as a developmental tool to reduce relative environmental pollution, industrial waste treatment cost, and delivery cost by optimizing material and energy flow exchanges in an industrial park. This model can maximize exchanges among industries to achieve a maximal recycling of the circulation.

Nevertheless, few studies have investigated the social performance of industrial parks. Although several scholars attempted to synthesize environment, facilities, business synergism, and green image into a framework to help companies gauge their goal of environmental stewardship [22], little consideration has been given to quantitative evaluation of the social aspects of industrial park performance, let alone the comprehensive performance integrating the social issues. The present study aims to develop a mathematical model (MILP-assembly line balance - ALB model) to respond to the above challenges. The developed model uses one comprehensive value to reflect the holistic performance of an industrial park, including economic, social, and environmental performance, and can be used for performance optimization.

The remainder of this paper is organized as follows. Section 3 presents the construction of the member assessment model to evaluate the comprehensive performance of each enterprise. In this section, the assembly line balancing (ALB) model and the MILP method are integrated to construct a model for evaluating the optimized comprehensive performance of an industrial park. In Section 4, the MILP-ALB model is applied in a real industrial park, and the model provides problem description, simulation procedures, and relevant data. Section 5 gives the 
results through a simulation. In section 6 , the most suitable new enterprise is obtained to introduce into the industrial park and the effectiveness of MILP-ALB model is examined through discussion about simulation results. Conclusions are summarized in Section 7.

\section{MODEL CONSTRUCTION}

\subsection{Member assessment model}

The member assessment model aims to make the comprehensive performance of the enterprise thoroughly characterize the benefits of each member enterprise on economy, society, and environment, as well as their interactions.

The economic performance of an enterprise, $f_{e c}$, is equal to the net profit $P_{n}$ divided by the total profit $P_{t}$ of the enterprise:

$$
f_{e c}=\frac{P_{n}}{P_{t}}
$$

The environmental performance of an enterprise in the industrial park, $f_{e n}$, can be shown as:

$$
f_{e n}=\frac{W_{u}}{W_{g}}
$$

where $W_{u}$ is the amount of waste utilization of the enterprise in the industrial park and $W_{g}$ is the total amount of waste generated by the enterprise before introduced into the industrial park.

$f_{s o}$ represents the social performance of an enterprise in the industrial park and is defined as:

$$
f_{s o}=\frac{E_{i}}{E_{t}} \times \alpha_{e}+\frac{T_{a}}{T_{t}} \times \alpha_{t}
$$

where $E_{i}$ is the increased amount of enterprise employment after the introduction of the enterprise to the industrial park, $E_{t}$ is the total employment of the enterprise, $T_{a}$ is the increase of national tax revenue caused by the introduction of the enterprise into the industrial park, $T_{t}$ is the total amount of tax of the enterprise in the industrial park, $\alpha_{e}$ is the weight of employment, and $\alpha_{t}$ is the weight of tax. In the social benefit analysis, employment and tax revenue play an equally significant role in the development of Chinese society. Thus, $\alpha_{e}=\alpha_{t}=0.5$ can be proposed.

To integrate the economic, environmental, and social performance of one enterprise, three coordinate axes are represented by $f_{e c}, f_{e n}$, and $f_{s o}$ in the 3D coordinate in Fig. 1; the measures of which are the same. The values of $f_{e c}, f_{e n}$, and $f_{s o}$ of an enterprise in the industrial park can be obtained using Eqs. (1) to (3) and are marked on the corresponding coordinate axis. By connecting the points of $f_{e c}, f_{e n}$, and $f_{s o}$ into lines, a triangular pyramid is obtained. Economic, social, and environmental performance can be expressed by the right-angle sides of the three rectangular pyramid. The comprehensive performance of the enterprise, $t_{i}$, can be calculated as the volume of the three rectangular pyramid and is dimensionless. The member assessment model can be written as:

$$
t_{i}=\frac{1}{6} \times f_{e c} \times f_{e n} \times f_{s o}
$$




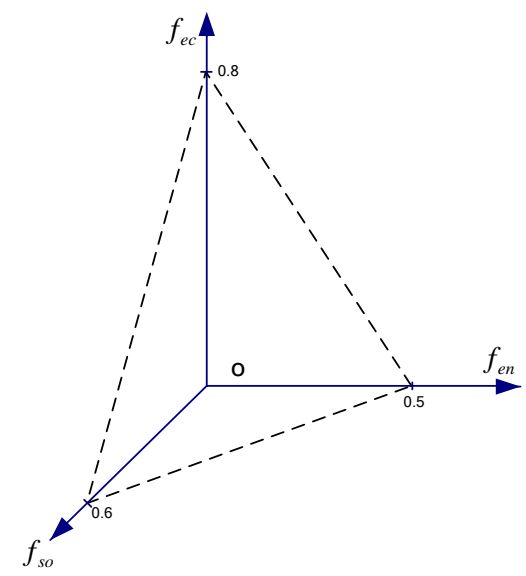

Figure 1: Comprehensive performance of enterprise A.

For example, in Fig. 1, the $f_{e c}, f_{e n}$, and $f_{s o}$ of enterprise $\mathrm{A}$ are $0.80,0.50$, and 0.60, respectively. According to Eq. (4), the comprehensive performance of enterprise A is:

$$
t_{i A}=\frac{1}{6} \times 0.8 \times 0.6 \times 0.5=0.04
$$

In industrial parks, the material, energy, and fund flows are along the industrial chain and move from one enterprise to another consecutively. By providing a comprehensive performance of member enterprises, the comprehensive performance of the industrial park can be further investigated.

\subsection{Mixed Integer Linear Programming-Assembly Line Balance (MILP-ALB) model}

An assembly line is a flow-oriented production system, in which the production units, referred to as stations, are arranged in a serial manner to perform assembly operations. The workpieces visit stations successively as they are moved along the line by the transportation system. An assembly line consists of (work) stations arranged along a conveyor belt, which delivers workpieces from one station to another. Manufacturing a product on an assembly line requires partitioning the total amount of work into a set of elementary operations named task. Precedence constraints between tasks can be observed by organizational conditions. Certain operations are performed repeatedly at each station, and the operation time determines the cycle time of the assembly line (maximum or average time available for each work cycle).

The industrial chain of an industrial park is similar to an assembly line in that material, energy, and fund flows are significant [23]. Stations of the assembly line are used to represent enterprises, and an industrial chain may consist of enterprises $k=\{1, \ldots, K\}$ arranged along the chain of the industrial park. The enterprises in an industrial park are strongly coupled to each other by the exchange of material, energy, or fund flow, which essentially constitute the industrial chain of the industrial park. The industrial park has its own comprehensive performance [24, 25], and a bottleneck effect is produced when the comprehensive performance of one member enterprise (i.e., $t_{i}$ ) is low [26]. This issue can be addressed by balancing the assembly line (ALB) model, which aims to support the decision maker in configuring the comprehensive performance of the industrial park.

Based on the ALB model which was proposed by Liu and Yu [27], the comprehensive performance of the industrial park and the interaction among enterprises in the industrial park can be described as follows:

$$
\left\{\begin{array}{l}
z^{\prime}=\sum_{k=1}^{K} X_{i k} t_{i} \quad(k \in K) \\
\sum_{k=1}^{K} X_{i k}=1 \quad(i \in K)
\end{array}\right.
$$


In Eq. (5), $X_{i k}$ represents the interaction between enterprise $i$ and enterprise $k$. If enterprise $i$ has no business with enterprise $k$, the value of $X_{i k}$ is zero, and otherwise, the value is 1 . $\sum_{k=1}^{K} X_{i k}=1$ means the interactions between the enterprises of the industrial park. The comprehensive performance of all the related enterprises is integrated to obtain the comprehensive performance of the industrial park (i.e., $z^{\prime}$ ), which can be expressed as $z^{\prime}=\sum_{k=1}^{K} X_{i k} t_{i}$.

To obtain the optimized comprehensive performance of the industrial park, we must obtain the optimal solution of Eq. (5). Thus, some binary variables $(0,1)$ are introduced:

$$
x_{i j}=\left\{\begin{array}{l}
1 \\
0
\end{array}\right.
$$

$x_{i j}=1$ means that there exits an direct interaction between enterprise $i$ and enterprise $j$ in the industrial chain, and $x_{i j}=0$ means no direct interaction. An industrial chain includes at least two enterprises, and thus we have the following equations:

$$
\begin{aligned}
& \sum_{j=1}^{n} x_{i j}=1 \quad i=1,2, \ldots, n \\
& \sum_{i=1}^{n} x_{i j}=1 \quad j=1,2, \ldots, n
\end{aligned}
$$

Meanwhile, sufficient constraints should be involved in this model to avoid subcirculation in the industrial chain. Thus, an extra variable $u_{i}(i=2,3, \ldots, n)$ is appended to the model. The $u_{i}$ variable is continuous, and it is an integer variable in the optimum solution. The constraint condition can be expressed as:

$$
u_{i}-u_{j}+n x_{i j} \leq n-1 \quad 2 \leq i \neq j \leq n
$$

Eq. (9) implies two issues. First, any sub-circulation in the industrial chain does not meet the constraint condition of Eq. (9) [Issue (1)]. Second, the constraint condition of Eq. (9) is met in the entire circulation of the industrial chain [Issue (2)].

Issue (1) is proved by the reductio ad absurdum. If a sub-circulation exists in the industrial chain, the sub-circulation does not contain at least a certain enterprise (for example, enterprise 1). Therefore, this sub-circulation can be marked as $i_{1} i_{2} \cdots i_{k} i_{1}$. The above conditions can be given as:

$$
\begin{aligned}
& u_{i_{1}}-u_{i_{2}}+n \leq n-1 \\
& u_{i_{2}}-u_{i_{3}}+n \leq n-1 \\
& \cdots \\
& u_{i_{k}}-u_{i_{1}}+n \leq n-1
\end{aligned}
$$

By adding the above formulas, we can obtain:

$$
n \leq n-1
$$

This is evidently unreasonable. Thus Issue (1) is proved.

Issue (2) is proved using the construction method. The sub industrial chains outside the circulation can be expressed as $1 i_{1} \cdots i_{n-1} 1 . u_{i}$ represents an enterprise's frequency of being flowed through by material, energy, and fund flows, the value range of which is $\{0,1, \cdots, n-2\}$. Thus:

$$
u_{i}-u_{j} \leq n-2 \quad 2 \leq i \neq j \leq n
$$


The relationships among the frequency of enterprises inside the circulation can be expressed as:

$$
\left\{\begin{array}{l}
u_{i_{1}}-u_{i_{2}}+n=n-1 \leq n-1 \\
u_{i_{2}}-u_{i_{3}}+n=n-1 \leq n-1 \\
\cdots \\
u_{i_{n-2}}-u_{i_{n-1}}+n=n-1 \leq n-1
\end{array}\right.
$$

The relationships among the frequency of enterprises outside the circulation can be expressed as:

$$
\left\{\begin{array}{l}
u_{i_{r}}-u_{j} \leq n-2 \leq n-1 \quad r=1,2, \ldots, n-2 \quad j \in\{2,3, \cdots, n\}-\left\{i_{r}, i_{r+1}\right\} \\
u_{i_{n-1}}-u_{j} \leq n-2 \leq n-1 \quad j \in\{2,3, \cdots, n\}-\left\{i_{r}\right\}
\end{array}\right.
$$

Any industrial chain (inside and outside the circulation) is evidently valid in Eq. (9). Issue 2 is proved.

On the basis of the foregoing discussions, Eq. (5) is translated into the MILP model, named the MILP-ALB model. The objective of the model is to solve the optimal solution of the comprehensive performance of the industrial park. More reasonable, whole chain indicates higher utilization and performance. The MILP-ALB model for obtaining the optimized comprehensive performance of the industrial park can be written as:

$$
\begin{aligned}
& z=\max z^{\prime}=\sum_{\substack{i, j=1 \\
i \neq j}}^{n} t_{i} x_{i j} \\
& \text { s.t. }\left\{\begin{array}{l}
\sum_{i=1}^{n} x_{i j}=1, \quad j=1,2, \cdots, n \\
\sum_{j=1}^{n} x_{i j}=1, \quad i=1,2, \cdots, n \\
u_{i}-u_{j}+n x_{i j} \leq n-1, \quad 2 \leq i \neq j \leq n \\
x_{i j}=0,1, \quad i, j=1,2, \cdots, n \\
u_{i} \geq 0, \quad i=2,3, \cdots, n
\end{array}\right.
\end{aligned}
$$

where $z$ is the optimized comprehensive performance of the industrial park and is dimensionless.

\section{CASE STUDY}

\subsection{Overview of Yingbin Industrial Park}

The MILP-ALB model is applied in Yingbin Industrial Park in Harbin, China. This park is located in the west of Daoli district of Harbin and is affiliated to Harbin High \& New Technology Industrial Development Zone. The park area is about 12.2 square kilometres. The enterprises in the industrial park include wood processing factory (WPF), paper mill (PM), printing house (PH), chemical building materials factory (FCBM), construction company (CC), pipe mill (PMI), air-conditioning equipment company (AEC), and equipment installing company (EIC). These enterprises produce different products and byproducts and constitute an industrial chain by exchanging materials, energy, and funds. The movements of material, energy, and fund flows are shown in Fig. 2. 


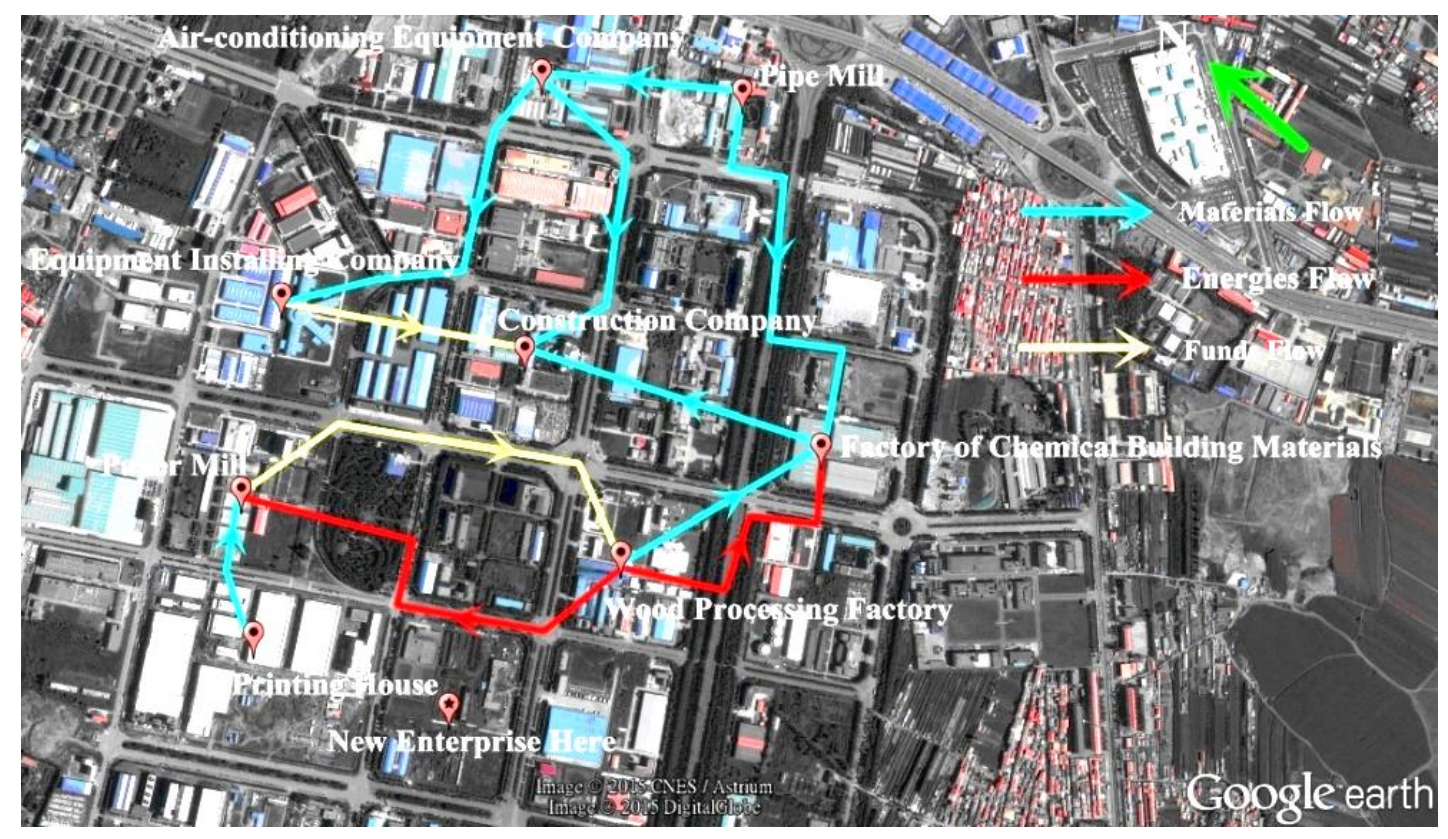

Figure 2: Aerial view of Yingbin Industrial Park.

\subsection{Formulation of problems}

The industrial park plans to introduce a salt plant (SP) to increase its performance significantly. The selection of the new enterprise depends on the comprehensive performance of the industrial park after its introduction. The one, which results in the highest performance of the park, should be introduced. Thus, the problem of selection per se is performance optimization. The industrial chain of the industrial park with SP is shown in Fig. 3.

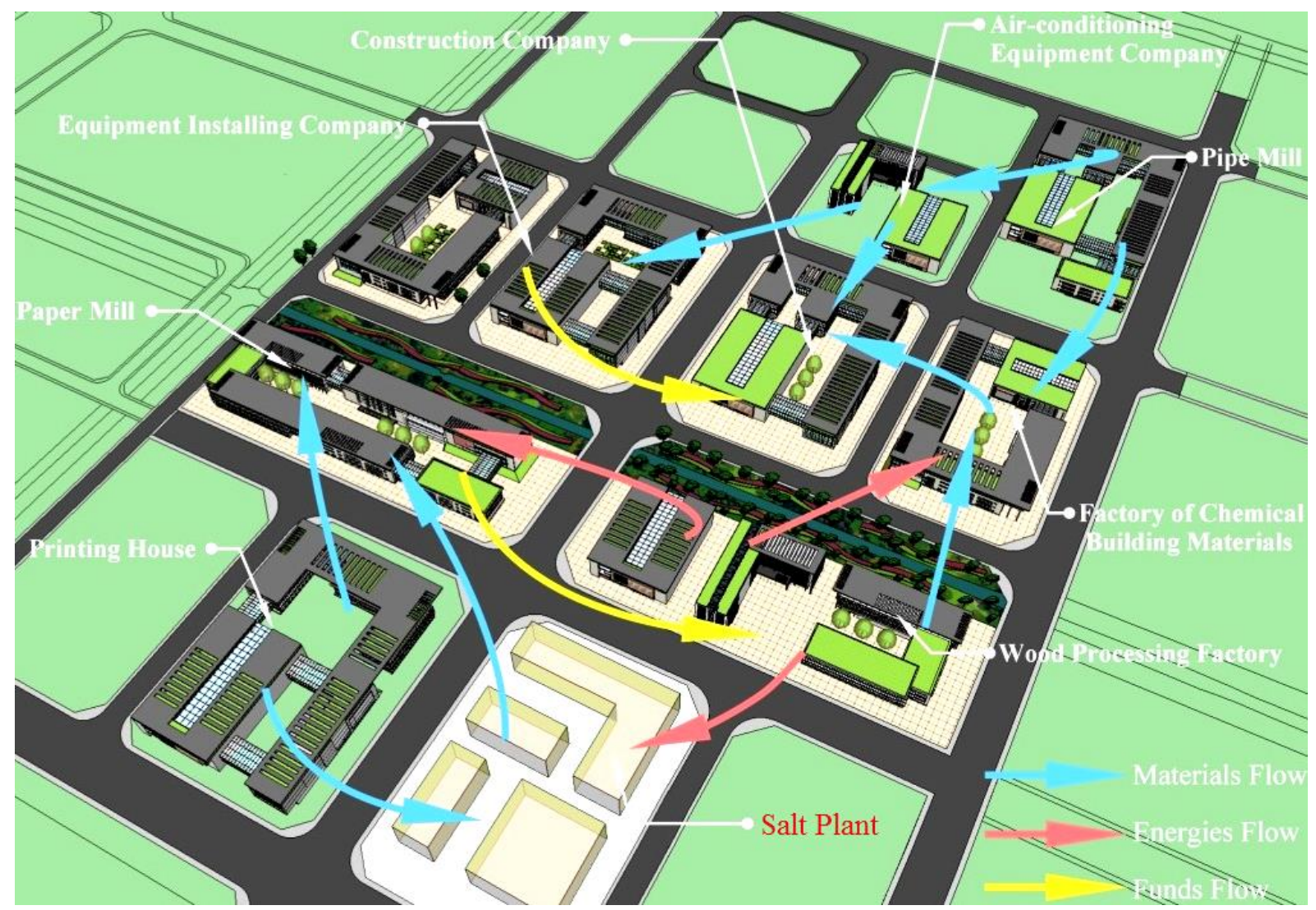

Figure 3: Topology graph of Yingbin Industrial Park (with the salt plant). 
Suppose that $t_{i}$ of SP $\left(t_{i S P}\right)$ starts from 0 , and it increases 0.0001 in each simulation calculation. The values of $t_{i S P}$ and $t_{i}$, and the directions of inflow and outflow of material, energy, and fund based on the industrial park topology graph are incorporated into the program code for the MILP-ALB model. The optimized comprehensive performance of the industrial park (i.e., $z$ ) is obtained by using the simulation technique. The change of the increase rate of $z$ is then simulated by changing $t_{i S P}$ to investigate the relationship between the comprehensive performance of the new enterprise and the optimized comprehensive performance of the industrial park.

Simulation is carried out as follows:

(1) Model transformation. The MILP-ALB model is translated into program codes by using the Linear Interactive and General Optimizer (LINGO) software. Eq. (15) is translated into computer language.

(2) Analyzing enterprise relationships. By depicting Yingbin Industrial Park topology graph, the material, energy, and fund flows in the industrial park are deciphered.

(3) Data collection. The data of the net profit $\left(P_{n}\right)$, total profit $\left(P_{t}\right)$, waste utilization $\left(W_{u}\right)$, total waste $\left(W_{g}\right)$, increase of employment $\left(E_{i}\right)$, total employment $\left(E_{t}\right)$, increase of national tax revenue $\left(T_{a}\right)$, and total tax $\left(T_{t}\right)$ of each enterprise are collected through survey or from statistical materials.

(4) The comprehensive performance of enterprises in Yingbin Industrial Park is calculated. The economic $\left(f_{e c}\right)$, environmental $\left(f_{e n}\right)$, and social performance $\left(f_{s o}\right)$ of each enterprise are calculated according to Eqs. (1) to (3). The comprehensive performance of the enterprise (i.e., $t_{i}$ ) is calculated according to Eq. (4).

(5) The optimized comprehensive performance of Yingbin Industrial Park is simulated. The comprehensive performance of enterprises and their relationships in the industrial park are inputted into the MILP-ALB model. The optimized comprehensive performance of Yingbin Industrial Park is then calculated using LINGO software on a Core $2.66 \mathrm{GHz}$ Windows PC with Intel Core®i5-750, 8 GBs RAM.

\subsection{Data collection and processing}

The data of $P_{n}, P_{t}, W_{u}, W_{g}, E_{i}, E_{t}, T_{a}$, and $T_{t}$ of each original enterprise of Yingbin Industrial Park are obtained from the Statistics Department of Harbin High \& New Technology Industrial Development Zone (Table I).

The $f_{e c}, f_{s o}, f_{e n}$, and $t_{i}$ of each original enterprise are calculated based on the data in Table I, and the results are shown in Table II.

\section{RESULT ANALYSIS}

\subsection{Simulation of the optimized comprehensive performance with different performance of SP}

The comprehensive performance of original enterprises is presented in Table II. The assumed value of the comprehensive performance of SP (i.e., $t_{i S P}$ ) and their relationships (see Fig. 3) into the MILP-ALB model, and the optimized comprehensive performance of the industrial park (i.e., $z$ ) can be calculated. The optimized comprehensive performance of the industrial park with SP is obtained with the increase of $t_{i S P}$ from zero. Simulation results illustrate the correlation between $z$ and $t_{i S P}$ (see Fig. 4).

As shown in Fig. 4, $z$ does not increase with the increase of $t_{i S P}$ when $t_{i S P}$ is small. A stepwise increase in $z$ can be found as $t_{i S P}$ increases. When $t_{i S P}$ is sufficiently large, an equal proportional relationship exists between the two values. 
Table I: Data of enterprises in Yingbin Industrial Park.

\begin{tabular}{|l|c|c|c|c|c|c|c|c|}
\hline \multicolumn{1}{|c|}{ Company } & WPF & PM & PH & FCBM & CC & PMI & AEC & EIC \\
\hline $\begin{array}{l}\text { Net profit } P_{n} \\
\text { (yuan per year) }\end{array}$ & $3.0 \times 10^{7}$ & $5.0 \times 10^{6}$ & $1.3 \times 10^{7}$ & $2.3 \times 10^{6}$ & $2.0 \times 10^{6}$ & $4.0 \times 10^{7}$ & $9.6 \times 10^{6}$ & $1.0 \times 10^{7}$ \\
\hline $\begin{array}{l}\text { Total profit } P_{t} \\
\text { (yuan per year) }\end{array}$ & $2.5 \times 10^{8}$ & $2.4 \times 10^{7}$ & $1.9 \times 10^{8}$ & $2.6 \times 10^{7}$ & $1.0 \times 10^{7}$ & $3.6 \times 10^{8}$ & $7.4 \times 10^{7}$ & $1.2 \times 10^{8}$ \\
\hline $\begin{array}{l}\text { Waste utilization } \\
W_{u}(\mathrm{~kg} \text { ) }\end{array}$ & $4.0 \times 10^{4}$ & $3.0 \times 10^{4}$ & $3.0 \times 10^{4}$ & $2.0 \times 10^{4}$ & $1.5 \times 10^{4}$ & $6.5 \times 10^{4}$ & $1.2 \times 10^{5}$ & $1.0 \times 10^{4}$ \\
\hline $\begin{array}{l}\text { Total waste } W_{g} \\
\text { (kg) }\end{array}$ & $1.0 \times 10^{5}$ & $9.0 \times 10^{4}$ & $5.0 \times 10^{4}$ & $9.5 \times 10^{4}$ & $6.0 \times 10^{4}$ & $1.0 \times 10^{5}$ & $3.0 \times 10^{5}$ & $3.0 \times 10^{4}$ \\
\hline $\begin{array}{l}\text { Increased amount } \\
\text { of employment } E_{i} \\
\text { (number of people) }\end{array}$ & 100 & 50 & 100 & 170 & 300 & 149 & 100 & 60 \\
\hline $\begin{array}{l}\text { The total } \\
\text { employment } E_{t} \\
\text { (number of people) }\end{array}$ & 900 & 350 & 1000 & 800 & 200 & 753 & 400 & 200 \\
\hline $\begin{array}{l}\text { Increase of } \\
\text { national tax } \\
\text { revenue } T_{a} \\
\text { (yuan per year) }\end{array}$ & $2.0 \times 10^{7}$ & $1.0 \times 10^{6}$ & $9.0 \times 10^{6}$ & $3.0 \times 10^{6}$ & $6.0 \times 10^{5}$ & $1.0 \times 10^{7}$ & $2.5 \times 10^{6}$ & $7.0 \times 10^{6}$ \\
\hline $\begin{array}{l}\text { Total tax } T_{t} \\
\text { (yuan per year) }\end{array}$ & $6.0 \times 10^{7}$ & $7.0 \times 10^{6}$ & $8.0 \times 10^{7}$ & $1.5 \times 10^{7}$ & $5.0 \times 10^{6}$ & $5.0 \times 10^{7}$ & $2.2 \times 10^{7}$ & $2.5 \times 10^{7}$ \\
\hline
\end{tabular}

Table II: Economic, environmental, social, and comprehensive performance of enterprises.

\begin{tabular}{|l|c|c|c|c|c|c|c|c|}
\hline \multicolumn{1}{|c|}{ Company } & WPF & PM & PH & FCBM & CC & PMI & AEC & EIC \\
\hline $\begin{array}{l}\text { Economic } \\
\text { performance } f_{e c} \\
\text { (dimensionless) }\end{array}$ & 0.12 & 0.21 & 0.07 & 0.09 & 0.2 & 0.11 & 0.13 & 0.08 \\
\hline $\begin{array}{l}\text { Environmental } \\
\text { performance } f_{e n} \\
\text { (dimensionless) }\end{array}$ & 0.4 & 0.3 & 0.6 & 0.21 & 0.25 & 0.65 & 0.4 & 0.33 \\
\hline $\begin{array}{l}\text { Social performance } \\
f_{\text {so } \text { (dimensionless) }}\end{array}$ & 0.22 & 0.14 & 0.11 & 0.21 & 0.14 & 0.2 & 0.18 & 0.29 \\
\hline $\begin{array}{l}\text { Comprehensive } \\
\text { performance of } \\
\text { member enterprises } \\
t_{i} \text { (dimensionless) }\end{array}$ & $1.8 \times 10^{-3}$ & $1.7 \times 10^{-3}$ & $7.0 \times 10^{-4}$ & $6.3 \times 10^{-4}$ & $1.1 \times 10^{-3}$ & $2.4 \times 10^{-3}$ & $1.6 \times 10^{-3}$ & $1.3 \times 10^{-3}$ \\
\hline
\end{tabular}

Fig. 5 depicts the increase rate of $z$ with increasing $t_{i S P}$ and characterizes the effect of the growth of the comprehensive performance of SP on the increase of the optimized comprehensive performance of the industrial park. By observing the relationship between $z$ and $t_{i S P}$, we can determine how the comprehensive performance of the new member affects the optimized comprehensive performance of the industrial park.

In Fig. 5, the increase rate of $z$ remains zero with relatively small $t_{i S P}$. The increase rate of $z$ fluctuates when $t_{i S P}$ increases. However, the increase rate of $z$ becomes stable when $t_{i S P}$ is sufficiently large (>0.0096 in this case). 


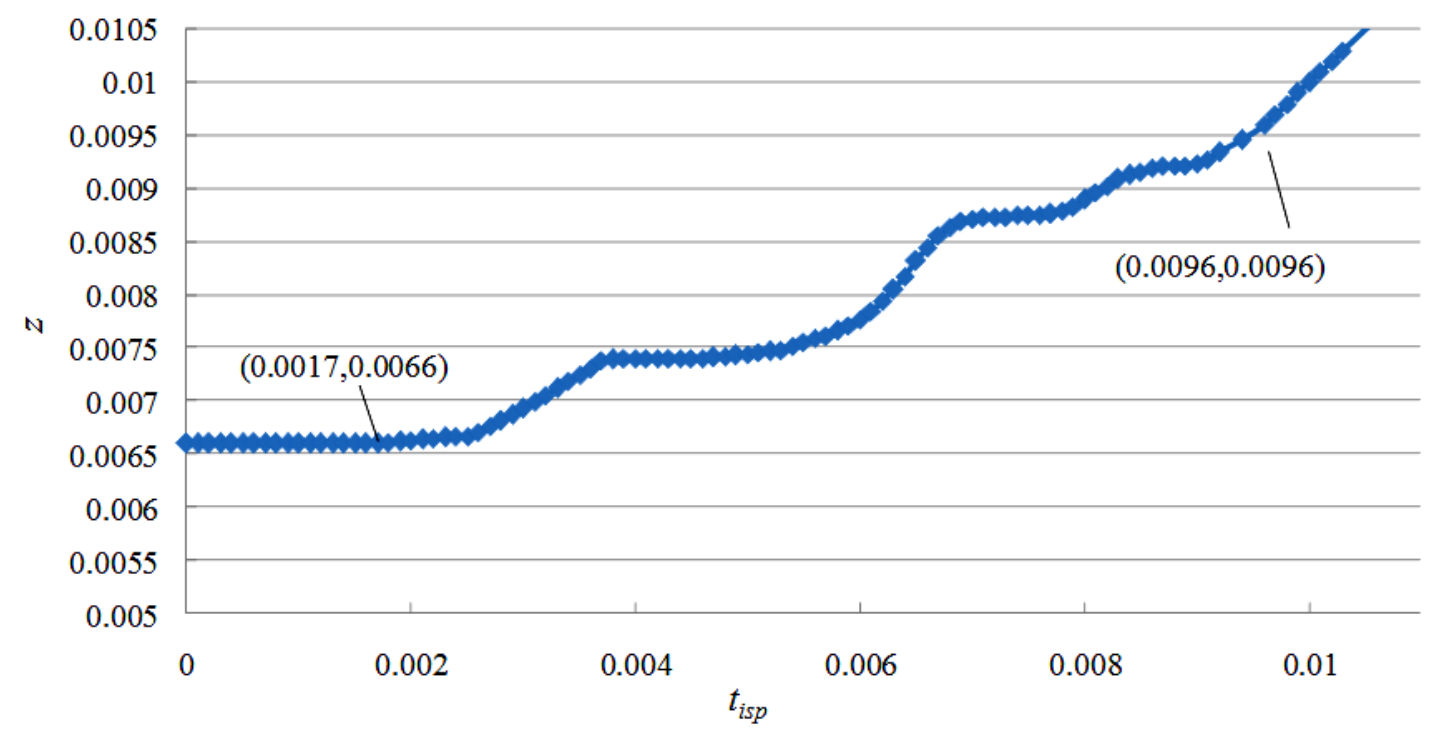

Figure 4: Changes of $z$ with $t_{i S P}$.

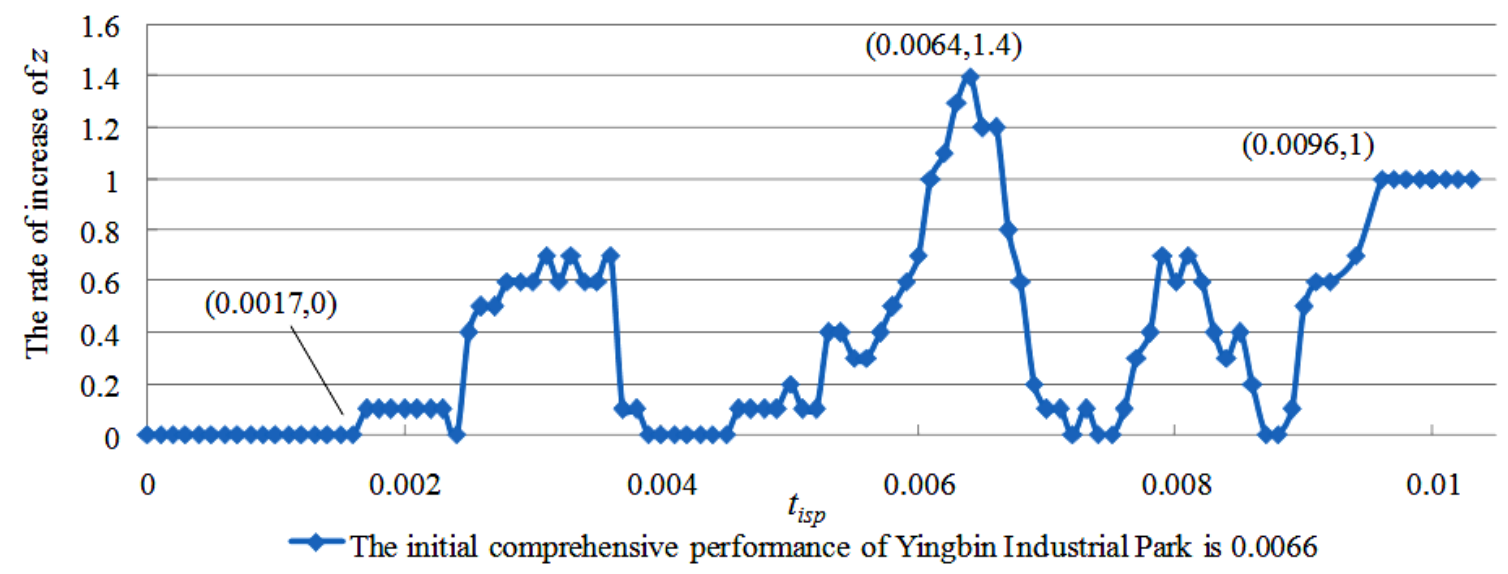

Figure 5: Changes of the increase rate of $z$ with $t_{i S P}$.

$t_{i S P}=0$ indicates that SP is not introduced into the industrial park, as shown in Figs. 4 and 5. Thus, the optimized comprehensive performance of the industrial park without SP is the initial comprehensive performance of Yingbin Industrial Park $(z=0.0066)$. Results show that the highest increase rate is 1.4 when the compressive performance of SP is 0.0064 , which is approximately equal to the initial performance of the industrial park of 0.0066 . In the succeeding section, the relationship between the initial performance of the industrial park and the comprehensive performance of SP is further investigated.

\subsection{Simulation of the optimized comprehensive performance with different initial comprehensive performance of the park}

Figs. 6 to 8 show the simulation results when the initial value of Yingbin Industrial Park comprehensive performance is $0.0020,0.0055,0.0090,0.01,0.1$, and 0.2 , respectively. Similar changes of the increase rate of $z$ with the increase of $t_{i S P}$ as shown in Fig. 5 can be observed. The increase rate of $z$ is equal to zero when the value of $t_{i S P}$ is small. With relatively large $t_{i S P}$, the increase rate of $z$ remains 1 . Furthermore, an approximately equal relationship exists between the initial comprehensive performance of Yingbin Industrial Park and $t_{i S P}$ when the increase rate of $z$ reaches the highest value. Simulation analysis of other initial values of Yingbin Industrial Park comprehensive performance exhibits similar results but is not graphically represented in this paper because of the large number of figures involved. 


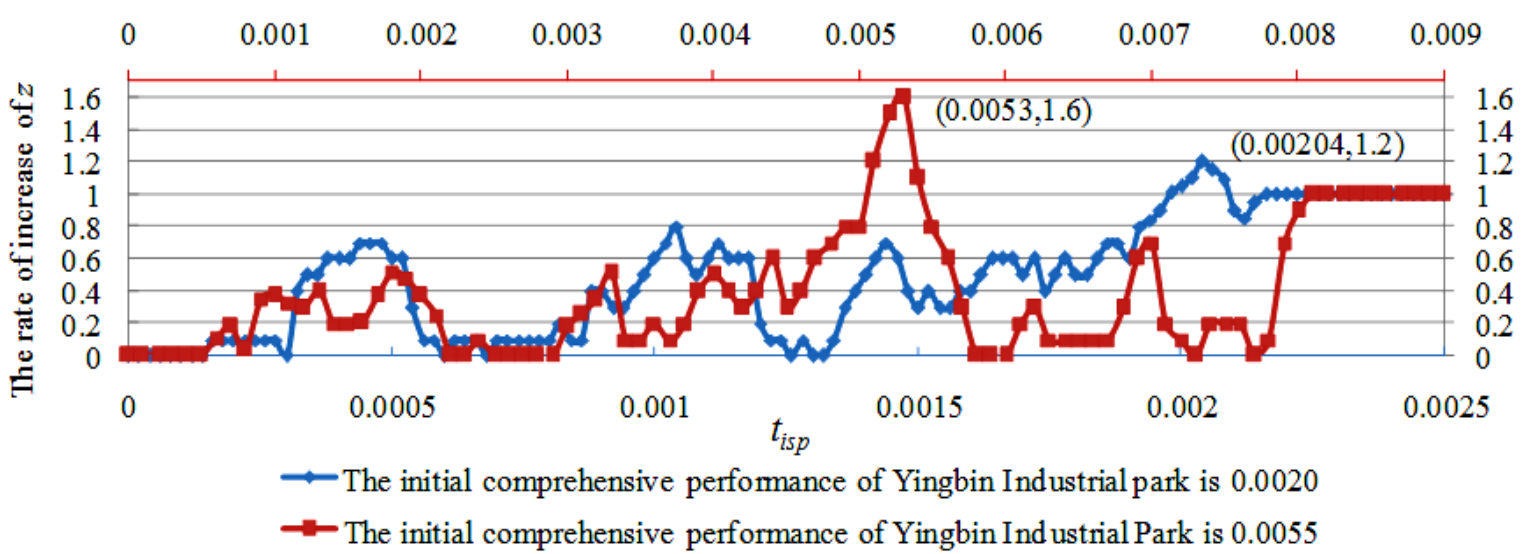

Figure 6: Changes of the increase rate of $z$ when its initial values are 0.0020 and 0.0055 .

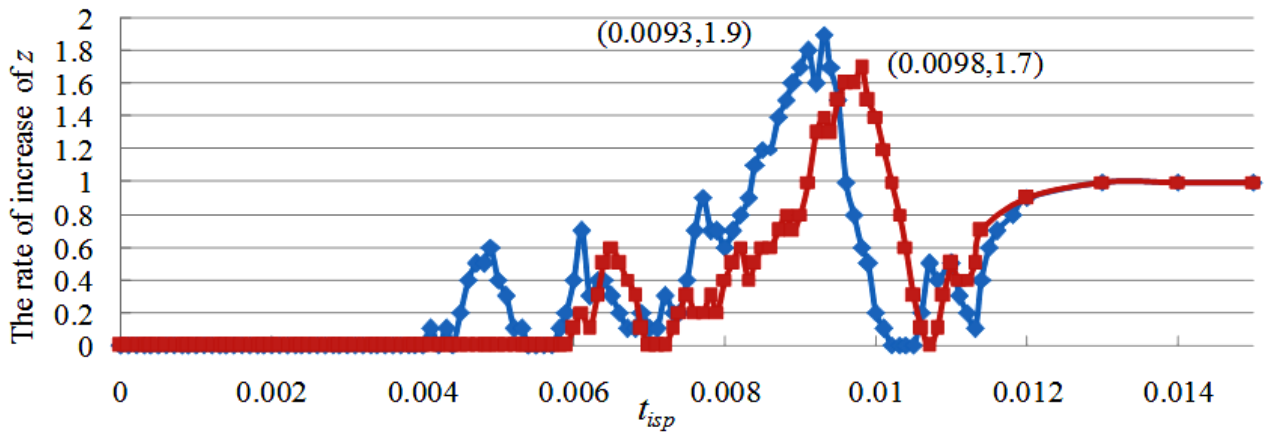

$\neg$ The initial comprehensive performance of Yingbin Industrial Park is 0.0090

$\rightarrow$ The initial comprehensive performance of Yingbin Industrial Park is 0.01

Figure 7: Changes of the increase rate of $z$ when its initial values are 0.009 and 0.01 .

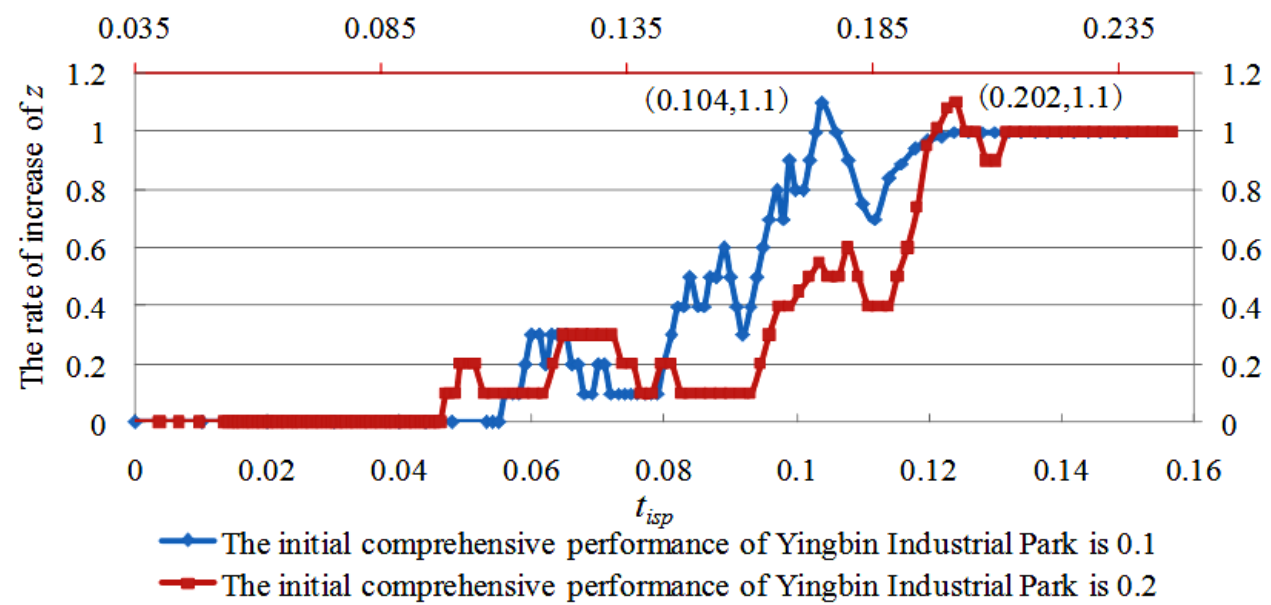

Figure 8: Changes of the increase rate of $z$ when its initial values are 0.1 and 0.2 .

\section{DISCUSSION}

As shown in Fig. 4, when $0<t_{i S P} \leq 0.0017, z$ remains 0.0066 . This finding indicates that the low-performance SP has no effect on the optimized comprehensive performance of the industrial park, even if the SP can extend the chain of the industrial park. When $0.0017<t_{i S P} \leq 0.0096$, the value of $z(0.0066<z<0.0096)$ increases with increasing $t_{i S P}$. This finding implies that the increase of the comprehensive performance of the new member results in the improvement of the optimized comprehensive performance of the industrial park when $t_{i S P}$ reaches a certain value $\left(t_{i S P}=0.0017\right)$. This trend is consistent with the actual 
situation. If the value of $t_{i S P}$ is greater than 0.0096 , then the value of $z$ is equal to $t_{i S P}\left(z=t_{i S P}\right.$, $\left.t_{i S P} \geq 0.0096\right)$. The equal relationship between $z$ and $t_{i S P}$ shows that after expanding $t_{i S P}$ to a certain extent $\left(t_{i S P} \geq 0.0096\right)$, the comprehensive performance of the new member (SP) represents the optimized comprehensive performance of the industrial park; that is, the industrial chain of the industrial park is dominated by high-performance SP.

Increasing the value of $t_{i S P}$ does not always result in the increase rate of $z$. For example, $z$ is equal to 0.0074 when $t_{i S P}$ is changed from 0.0039 to 0.0045 ; thus, the increase rate of $z$ remains 0 (see Fig. 5). As previously discussed, low-performance SP cannot increase the optimized comprehensive performance of the industrial park. Fig. 5 shows that the increase rate of $z$ is equal to zero when the performance of SP is less than 0.0017. High-performance SP can increase the optimized comprehensive performance of the industrial park, but the increase rate of $z$ remains 1 . The increase rate of $z$ reaches the maximum value $(z=1.4)$ when $t_{i S P}=0.0064$ (see Fig. 5). From the optimization perspective, the increase rate of performance is more important than the performance itself. Thus, we argue that SP with performance of 0.0064 can most greatly help the industrial park achieve performance optimization. A unique best SP apparently exists among the medium-performance SPs $\left(0.0017<t_{i S P}<0.0096\right)$, the comprehensive performance of which corresponds to the maximum increase rate of the optimized comprehensive performance of the industrial park.

In summary, the simulation results indicate that low-performance SP has no effect on the optimized comprehensive performance of Yingbin Industrial Park. High-performance SP can dominate the industrial chain of Yingbin Industrial Park. The increase rate of the comprehensive performance of Yingbin Industrial Park can reach the maximum only when the comprehensive performance of SP is within the medium-performance range. The most suitable SP can greatly help Yingbin Industrial Park achieve performance optimization, when its comprehensive performance and the initial comprehensive performance of Yingbin Industrial Park are approximately equal to each other. These findings can be further proved by the changes of the increase rate of the optimized comprehensive performance of Yingbin Industrial Park with different initial comprehensive performance of the park (see Figs. 6 to 8).

SP significantly increases the increase rate of the comprehensive performance of Yingbin Industrial Park, when its comprehensive performance is 0.0064 . SP with this performance is the most suitable new enterprise for Yingbin Industrial Park. Basing on this result, Yingbin Industrial Park has introduced a suitable SP. The data of the first six months obtained from the Statistics Department of Harbin High \& New Technology Industrial Development Zone show that the performance of Yingbin Industrial Park has improved remarkably. Thus, the simulation results of the MILP-ALB model fit the facts, indicating the effectiveness of the proposed model.

\section{CONCLUSION}

To optimize the comprehensive performance of the industrial park, this paper constructs the MILP-ALB model and tests the model through simulation. The following conclusions are obtained:

(1) The comprehensive performance of enterprises of the industrial park, including economic, social, and environmental performance, can be expressed and calculated by the member assessment model.

(2) The comprehensive performance of the industrial park is affected by the performance of enterprises and their interactions and can be calculated based on the ALB model.

(3) By applying the MILP method, the MILP-ALB model can be constructed to obtain the optimized comprehensive performance of the industrial park. 
(4) The simulation results show that the MILP-ALB model can reveal the relationship between the optimized comprehensive performance of the industrial park and the comprehensive performance of the new introduced enterprise. Thus, the model is a useful tool for managers to select appropriate enterprises into the industrial park to achieve performance optimization.

The program code used in this paper is still preliminary. For example, when the number of enterprise in the industrial park is greater than 512, the size of the MILP-ALB model is large in LINGO and thus solving the model is difficult. Further studies on programming algorithm optimization for the MILP-ALB model should be considered in the future.

\section{ACKNOWLEDGEMENT}

This work was supported by the National Natural Science Foundation of China $(71472055,71002061$, 51508140), the National Science Foundation for Post-doctoral Scientists of China (20090460896, 201104424), the Science Foundation for Young Scholars of Heilongjiang Province (QC2009C109), the Heilongjiang Philosophy and Social Science Research Project (14B105), the Science Foundation for Post-Doctoral Scientists of Heilongjiang Province (LBH-Z09138), and the Project - sponsored by the Scientific Research Foundation for the Returned Overseas Chinese Scholars, State Education Ministry.

\section{REFERENCES}

[1] Frosch, R. A.; Gallopoulos, N. E. (1989). Strategies for manufacturing, Scientific American, Vol. 261, No. 3, 144-152, doi:10.1038/scientificamerican0989-144

[2] Bikiaris, D. N. (2011). Solid dispersions, part II: new strategies in manufacturing methods for dissolution rate enhancement of poorly water-soluble drugs, Expert Opinion on Drug Delivery, Vol. 8, No. 12, 1663-1680, doi:10.1517/17425247.2011.618182

[3] Taskhiri, M. S.; Tan, R. R.; Chiu, A. S. F. (2011). Emergy-based fuzzy optimization approach for water reuse in an eco-industrial park, Resources, Conservation and Recycling, Vol. 55, No. 7, 730-737, doi:10.1016/j.resconrec.2011.03.001

[4] Ageron, B.; Gunasekaran, A.; Spalanzani, A. (2012). Sustainable supply management: an empirical study, International Journal of Production Economics, Vol. 140, No. 1, 168-182, doi:10.1016/j.ijpe.2011.04.007

[5] Zhang, X.-H.; Wu, L.-Q.; Zhang, R.; Deng, S.-H.; Zhang, Y.-Z.; Wu, J.; Li, Y.-W.; Lin, L.-L.; Li, L.; Wang, Y.-J.; Wang, L.-L. (2013). Evaluating the relationships among economic growth, energy consumption, air emissions and air environmental protection investment in China, Renewable and Sustainable Energy Reviews, Vol. 18, 259-270, doi:10.1016/j.rser.2012.10.029

[6] Islam, S. (2011). Traditional urban planning approaches and sustainable city, Open House International, Vol. 36, No. 2, 15-23

[7] Lenzen, M. (2011). Aggregation versus disaggregation in input-output analysis of the environment, Economic Systems Research, Vol. 23, No. 1, 73-89, doi:10.1080/ $\underline{09535314.2010 .548793}$

[8] Lindner, S.; Legault, J.; Guan, D. (2013). Disaggregating the electricity sector of China's inputoutput table for improved environmental life-cycle assessment, Economic Systems Research, Vol. 25, No. 3, 300-320, doi:10.1080/09535314.2012.746646

[9] Haskins, C. (2007). A systems engineering framework for eco-industrial park formation, Systems Engineering, Vol. 10, No. 1, 83-97, doi:10.1002/sys.20063

[10] Krupa, M. B.; Chapin III, F. S.; Lovecraft, A. L. (2014). Robustness or resilience? Managing the intersection of ecology and engineering in an urban Alaskan fishery, Ecology and Society, Vol. 19, No. 2, paper 17, 9 pages, doi:10.5751/ES-06274-190217

[11] Ehrenfeld, J. R. (2007). Would industrial ecology exist without sustainability in the background?, Journal of Industrial Ecology, Vol. 11, No. 1, 73-84, doi:10.1162/jiec.2007.1177 
[12] Ketchen Jr., D. J.; Hult, G. T. M. (2007). Bridging organization theory and supply chain management: the case of best value supply chains, Journal of Operations Management, Vol. 25, No. 2, 573-580, doi:10.1016/j.jom.2006.05.010

[13] Jans, R.; Degraeve, Z. (2008). Modeling industrial lot sizing problems: a review, International Journal of Production Research, Vol. 46, No. 6, 1619-1643, doi:10.1080/00207540600902262

[14] Akartunal1, K.; Miller, A. J. (2012). A computational analysis of lower bounds for big bucket production planning problems, Computational Optimization and Applications, Vol. 53, No. 3, 729-753, doi:10.1007/s10589-012-9465-Z

[15] Kong, H.-N.; Qi, E.-S.; Li, H.; Li, G.; Zhang, X. (2010). An MILP model for optimization of byproduct gases in the integrated iron and steel plant, Applied Energy, Vol. 87, No. 7, 2156-2163, doi:10.1016/j.apenergy.2009.11.031

[16] Taskhiri, M. S.; Tan, R. R.; Chiu, A. S. F. (2011). MILP model for emergy optimization in EIP water networks, Clean Technologies and Environmental Policy, Vol. 13, No. 5, 703-712, doi:10.1007/s10098-010-0341-1

[17] Tian, X.-K.; Zhao, R.-Y. (2015). Energy network flow model and optimization based on energy hub for Big Harbor Industrial Park, Journal of Coastal Research, Special issue 73, 298-303, doi:10.2112/SI73-052.1

[18] Shepherd, D. A.; Patzelt, H. (2011). The new field of sustainable entrepreneurship: studying entrepreneurial action linking "what is to be sustained" with "what is to be developed", Entrepreneurship Theory and Practice, Vol. 35, No. 1, 137-163, doi:10.1111/j.15406520.2010.00426.x

[19] Koukoumpliakos, I.; Nousia, M. (2008). The human growth and the healthy environment as a condition of balanced development for the course of human, Journal of Engineering Science and Technology Review, Vol. 1, 49-52

[20] Aviso, K. B.; Tan, R. R.; Culaba, A. B.; Cruz Jr., J. B. (2010). Bi-level fuzzy optimization approach for water exchange in eco-industrial parks, Process Safety and Environmental Protection, Vol. 88, No. 1, 31-40, doi:10.1016/j.psep.2009.11.003

[21] Gu, C.; Leveneur, S.; Estel, L.; Yassine, A. (2013). Modeling and optimization of material/energy flow exchanges in an eco-industrial park, Energy Procedia, Vol. 36, 243-252, doi:10.1016/j.egypro.2013.07.028

[22] Dean, C. A.; Fath, B. D.; Chen, B. (2014). Indicators for an expanded business operations model to evaluate eco-smart corporate communities, Ecological Indicators, Vol. 47, 137-148, doi:10.1016/j.ecolind.2014.07.010

[23] Mahmoudi, H.; Fazlollahtabar, H.; Mahdavi, I. (2013). Mathematical modeling for minimizing costs in a multilayer multi-product reverse supply chain, Industrial Engineering \& Management, Vol. 2, No. 2, 6 pages, doi:10.4172/2169-0316.1000105

[24] Kantor, I.; Fowler, M.; Elkamel, A. (2012). Optimized production of hydrogen in an eco-park network accounting for life-cycle emissions and profit, International Journal of Hydrogen Energy, Vol. 37, No. 6, 5347-5359, doi:10.1016/j.ijhydene.2011.08.084

[25] Eckelman, M. J.; Chertow, M. R. (2013). Life cycle energy and environmental benefits of a US industrial symbiosis, The International Journal of Life Cycle Assessment, Vol. 18, No. 8, 15241532, doi:10.1007/s11367-013-0601-5

[26] Kantor, I.; Elkamel, A.; Fowler, M. W. (2014). Optimisation of material and energy exchange in an eco-park network considering three fuel sources, International Journal of Advanced Operations Management, Vol. 6, No. 4, 285-308, doi:10.1504/IJAOM.2014.066828

[27] Liu, F.-L.; Yu, X.-J. (2013). An ALB model of eco-industrial parks, Applied Mechanics and Materials, Vol. 274, 485-489, doi:10.4028/www.scientific.net/AMM.274.485 